\title{
O COMPARTILHAR ESPAÇO/TEMPO ENTRE PESSOAS DOENTES HOSPITALIZADAS ${ }^{1}$
}

\author{
Roseney Bellato ${ }^{2}$
}

Emilia Campos de Carvalho ${ }^{3}$

Bellato R, Carvalho EC. O compartilhar espaço/tempo entre pessoas doentes hospitalizadas. Rev Latino-am Enfermagem 2002 março-abril; 10(2):151-6.

Através de uma abordagem compreensiva e tendo por base teórica os estudos de Michel Maffesoli, buscamos compreender a dimensão do compartilhar entre as pessoas doentes durante a hospitalização. Através de entrevistas e observações, pudemos apreender que a despeito de toda a normatização da hospitalização, as pessoas tecem uma teia relacional constituindo uma "comunidade de destino" dentro do hospital.

DESCRITORES: enfermagem, hospitalização, atividades cotidianas

\section{SPACE/TIME SHARING AMONG HOSPITALIZED ILL PEOPLE}

By means of a comprehensive approach and based on the theoretical framework stemming from the studies of Michel Maffesoli, we attempted to understand the sharing dimension existing among ill people during hospitalization. Through interviews and observation, we were able to apprehend that, in spite of all the standardization of hospitalization, people weave a relational web and engender a "destination community" within the hospital.

DESCRIPTORS: nursing, hospitalization, daily activities

\section{EL COMPARTIR ESPACIO/TIEMPO ENTRE LAS PERSONAS ENFERMAS HOSPITALIZADAS}

Por medio de un abordaje comprensivo y teniendo como base teórica los estudios de Michel Maffesoli, buscamos comprender la dimensión del compartir entre personas enfermas durante la hospitalización. A través de entrevistas y observaciones pudimos aprehender que a pesar de toda la normatividad de la hospitalización las personas tejen una tela relacional constituyendo una "comunidad de destino" dentro del Hospital.

DESCRIPTORES: enfermeria, hospitalización, actividades cotidianas

\footnotetext{
${ }^{1}$ Artigo baseado na Tese de Doutorado: Bellato R. A vivência da hospitalização pela pessoa doente. [tese]. Ribeirão Preto (SP): Escola de Enfermagem de Ribeirão Preto/USP; 2001; ${ }^{2}$ Doutora em Enfermagem Fundamental, Professor Adjunto I do Departamento de Enfermagem Médico-Cirúrgica da Faculdade de Enfermagem e Nutrição da Universidade Federal de Mato Grosso, e-mail: roseney@zaz.com.br; ${ }^{3}$ Professor Titular, Orientadora do Programa de Pós-Graduação da Área Enfermagem Fundamental da Escola de Enfermagem de Ribeirão Preto da Universidade de São Paulo, Centro Colaborador da OMS para o desenvolvimento da pesquisa em enfermagem
} 


\section{O CAMINHO TRACEJADO EM DIREÇÃO AO COMPARTILHAR}

$\boldsymbol{E}_{\text {ste estudo é parte de outro maior, constituído por uma }}$ tese de doutorado, e foi realizado com base em dados colhidos junto a sete pessoas doentes, hospitalizadas na clínica médica de um hospital universitário da região centro-oeste do Brasil. Nele procuramos compreender o significado da vivência da hospitalização para essas pessoas. Após obtermos o consentimento da Comissão de Ética da instituição, para que pudéssemos realizá-lo, empreendemos o trabalho de campo, empregando a entrevista e a observação como estratégias para coleta dos dados.

Por meio de uma abordagem compreensiva, respaldada, principalmente, por estudiosos franceses, tais como Michel Maffesoli, Gaston Bachelard, Louis-Vincent Thomas, Edgar Morin, entre outros, e empregando a noção de Forma, trazida por Georg Simmel, pudemos ordenar os dados obtidos em grandes configurações que se apresentaram como o espaço, o tempo, a morte e o quotidiano, possibilitando-nos compreender parte do vivenciar a hospitalização pela pessoa doente.

Nessa busca pela compreensão, o compartilhar emergiu como um "resíduo", mostrando que, mesmo em espaços aparentemente mais áridos, onde o que se tem para oferecer é, não raro, o sofrimento e a dor, também a afetividade, a empatia, a compaixão, o gostar e não-gostar fazem-se presentes e preenchem os interstícios do mundo do Hospital.

Se, a princípio, parecia-nos que a vivência da hospitalização seguia uma lógica mecânica, pautando-se apenas na divisão de um mesmo e exíguo espaço com outras pessoas estranhas, outra foi, no entanto, a face que nos foi apresentada nas narrativas e observações das situações vividas pela pessoa doente hospitalizada. Essa apresentação, porém, não se deu de maneira clara, direta, pensada. Ela foi se revelando por meio de pequenas atitudes, gestos, meias palavras, dispersos nas narrativas e nas muitas situações observadas no dia-a-dia da hospitalização.

Foi necessário que compreendêssemos, também, que 0 compartilhar, seja espaço, tempo, afeto, é sempre conflitual, pois ele não acontece numa dimensão regida apenas pelo racional, pelo lógico, pelo previsto. Abarcando outros valores, o compartilhar segue um trajeto em pontilhado, cujo traçado se faz no próprio espaçol tempo da partilha. Para buscar tal compreensão, ainda que de maneira parcial, apoiamo-nos, teoricamente, em Michel Maffesoli, uma vez que esse estudioso da vida quotidiana tem, como um dos fulcros de seu pensamento, a socialidade que alicerça as relações, trazendo no seu bojo a proximidade, a necessidade do ser/estar junto e de pertencer a um grupo, constituindo-se na proxemia ${ }^{(1)}$. No entanto, longe de ser repousante, a socialidade embasa-se na harmonia diferencial, na imperfeição, na incompletude de cada um, e nesse jogo da diferença, a troca (de afetos, de palavras, de experiências) é sua expressão mais completa. Mas, exatamente porque há diferença, a troca é, no mais das vezes, desigual, engajando elementos incompletos, sendo fundada, sobretudo, na disparidade, na heterogeneidade entre o que é dado (dom) e o que é recebido (contradom), não lhe cabendo, porém, uma valoração moral. Pois, sendo o ser humano infinitamente limitado, para superar essa pobreza essencial, ele institui a troca com os outros, com a alteridade, inaugurando a comunidade ${ }^{(1)}$.

Mas, a troca, a pluralidade e o jogo da diferença mostramnos que a socialidade tem como única dimensão a imediaticidade da partilha, o aqui e agora do tempo presente, que não se deixa postergar. E a pessoa doente hospitalizada, sabedora da precariedade da existência, não espera a realização de grandes amanhãs que cantam, para pôr em prática a partilha, a troca em que se funda o seu viver coletivo. O tempo presente da hospitalização e o lugar que se partilha, ainda que seja o estreito espaço de uma enfermaria, formam 0 substrato concreto da socialidade presente nesse vivenciar o mundo do Hospital, junto às demais pessoas doentes.

Se a presença da família não pode ser constante junto à pessoa doente durante a hospitalização, de maneira a aplacar-lhe a solidão, é necessário que ela encontre outras formas de ser/estar junto, de compartilhar, visto que faz parte da estrutura antropológica o viver coletivo, pois só podemos existir na medida em que fazemos parte de uma ordem, na qual integramos nossa diferença assumida num todo, que vai além de nós. Claro que tal visão não é verbalizada sob essa forma, sendo vivida quase que intencionalmente, traduzindose no profundo pluralismo e politeísmo de valores que impregnam a vida social ${ }^{(2)}$.

Mas, em que consiste esse con-viver com as demais pessoas doentes, quando se está no Hospital? Em que bases se apoia essa interação que se inicia com a imposição da presença do outro, no mesmo espaço representado pela enfermaria?

\section{A COMUNIDADE DE DESTINO}

O estar doente, o estar em um ambiente que não é o seu, de precisar submeter-se às normatizações do Hospital, impõe limitações e dificuldades ao compartilhar espaço/tempo, sendo necessário negociações, "jeitinhos", arranjos, para acomodar os interesses diversos.

Há coisas que se, podem fazer para o Hospital ser um lugar um pouco mais agradável, como há coisas que não é possivel fazer. Há pessoas que sabem aproveitar esse momento agradável e há pessoas que já não sabem, vão logo querendo bagunçar, né. Porque vê que está em ordem e 
vai já bagunçar com a ordem. É por isso que, muitas vezes, é tirado qualquer tipo de diversão ou entretenimento das pessoas. É tirado por causa daquelas que não entendem o que é entretenimento, acham logo que é uma bagunça. Então se torna uma coisa difíil de contentar todo mundo. Que nem ver televisão no quarto, no caso aqui da enfermaria, deixa ligada, aí, quando termina um programa, outros querem outro programa, outros já querem dormir. Se todo mundo aceitasse até às vinte e duas horas vamos assistir, das vinte e duas em diante é cama pra todo mundo, né. Porque uns querem e outros não querem. Acho difícil, no Hospital, manter, a não ser que faça uma sala que pudesse pôr lá umas poltronas e a televisão, quem quer ir lá vai, só que tá sabendo que vinte e duas horas está apagado, não tem nada, acabou. Ai até que daria, né. Mas liberar a televisão no quarto, isso não funciona, as pessoas não entendem, acham que podem amanhecer o dia. Mas tem aquelas que não, né. É uma coisa difíiil. (GILDA)*

Assuntos corriqueiros como decidir se vai ou não haver televisão na enfermaria ganham uma grande importância, pois as opiniões divergem, as necessidades variam, assim como o grau de tolerância e aceitação do outro diferente. Contudo, como em uma família, cada um tem direito a expor seu ponto de vista, ainda que não se chegue a um acordo que agrade a todos.

Na enfermaria feminina presenciei uma discussão entre a $D$. Gilda e outra mulher hospitalizada na cama ao lado, quanto a trazer ou não uma televisão para a enfermaria. A outra mulher dizia que a enfermeira havia sugerido que, se alguma delas quisesse, poderia trazer uma televisão para que pudessem se distrair e que ela tinha uma que poderia pedir para a sua família trazer. A D. Gilda, no entanto, questionava se isso não iria acarretar problemas, 'porque tinha gente que iria deixar a TV ligada até altas horas da noite e atrapalharia o sono das demais', referindo-se claramente à Rosana e a sua irmã. A outra mulher argumentava que se poderia conversar e chegar a um acordo para que se pudesse assistir à TV durante o dia e, quando alguém fosse dormir, seria desligada. A D. Gilda mostrava-se bastante resistente à idéia e dizia que ninguém poderia garantir que seria dessa forma, pois 'a juventude está acostumada a assistir TV até tarde, e que os bons filmes passam tarde da noite e, nesse caso, a TV ficaria ligada até de madrugada, atrapalhando o sono das outras'. Afirmava, ainda, ter dificuldade para dormir e que o barulho da TV só atrapalharia. Como eu estivesse observando a discussão, as duas mulheres se voltaram para mim, como querendo que eu arbitrasse sobre o assunto. Achei melhor não emitir opinião e disse apenas que elas é que precisariam decidir esse impasse. Nesse momento, uma auxiliar de enfermagem entrou com a bandeja de medicação do horário, e a discussão foi interrompida. (NOTAS DE OBSERVAÇÃO-08/ $02 / 99)^{\star \star}$

Se o compartilhar é sempre conflitual, é preciso, no entanto, encontrar um modus vivendi que busque a acomodação de valores e desejos diferentes. É necessário lembrar, também, que só podemos ser nós mesmos pelo outro, pois, ao transcender a si próprio, o indivíduo se agrega a outros elementos contraditórios para formar um todo que, por seu turno, valoriza a existência ${ }^{(2)}$. É preciso notar, também, que pluralidade e alteridade se complementam, e a arte da conjugação administra e respeita o conflito que o pluralismo gera. Apesar de ser conflitual o conviver, a diferença é ainda mais bem negociada que a solidão.

De primeiro, eu ficava mais só, né. Logo que eu cheguei, meu quarto estava cheio, aí logo esvaziou, todo mundo foi embora, e eu fiquei sozinha no quarto. Aí me trocaram de quarto, que tinha só uma senhora. Depois essa senhora foi embora, e eu fiquei de novo sozinha. Depois, encheu, esvaziou, eu ficando só. (...) Era até ruim ficar sozinha, vendo as paredes. Mas, quando tá cheio, aí fica melhor, né. A gente vai conversando, tudo. (ROSANA)

O território, esse espaço do ser/estar junto, permite a comunhão com o outro, não em função de um ideal longínquo, mas em referência aos valores vividos no presente. Ao mesmo tempo, esse lugar que se divide com o outro, permite "adoçar" a carga trágica ligada justamente ao presenteísmo. É bem do sentido trágico viver, no dia-a-dia, os problemas da existência, integrando-os, homeopaticamente, a ela, e não esperando uma solução definitiva e postergada para o amanhã $\tilde{~}^{(3)}$. Assim, entre o "estar só" e o "estar com o outro", vivem-se os dois, embora o compartilhar amenize a solidão. E o que se compartilha nessa vivência da hospitalização?

Aqui, ontem e hoje, é que a gente começou a dar mais risadas com a mulher ali, que estava com menos dor. Ela gosta de contar causos, dar risada. Porque as outras aqui, elas são mais diferentes, são mais quietinhas, né. Não são de muita conversa. (...) Ir sozinha lá na pracinha, também não tem ninguém, e ficar sentada lá é ruim, né, não tem com quem conversar. (MARIA IVONE)

Hoje, após a entrevista com o Ifigênio, ele permaneceu sentado comigo na área externa e ficamos conversando por um tempo. Logo em seguida, a Maria Ivone e o Waldecir aproximaram-se e sentaram-se, também, sob o quiosque onde estávamos. Ficamos, então, conversando e, aos poucos, outras pessoas foram se juntando a nós, tanto pessoas doentes quanto acompanhantes. Permanecemos ali por, mais ou menos, uma hora e meia, conversando sobre assuntos diversos, trocando impressões sobre fatos quotidianos de cada um, suas preferências, afazeres, lazeres, etc. Pouco se falou da vivência da hospitalização, parecendo não ser um assunto propício para aquele momento tão agradável que estávamos tendo. Quando o grupo foi se dispersando, pois começava a chover, comentei com o Ifigênio e a Maria Ivone que me parecia que as pessoas tinham vindo para a área externa porque nos viram ali reunidos. O Ifigênio comentou que, de fato, às vezes,

\footnotetext{
* Os nomes empregados neste estudo são fictícios de maneira a preservar o anonimato das pessoas doentes hospitalizadas que foram entrevistadas

** A designação "Notas de Observação" referem-se aos relatos feitos pela autora com base nas observações realizadas durante o trabalho de campo
} 
passava pela pracinha e, se via mais alguém ali, ficava, caso contrário ia embora. A Maria Ivone concordou dizendo que, quando queria vir para a pracinha, sempre convidava uma colega de quarto para vir também, pois era ruim ficar ali sozinha. (NOTAS DE OBSERVAÇÃO - 26/01/99)

Também no Hospital, o quotidiano se faz de momentos banais, fugazes, que se constroem no aqui e agora, no imediatismo do instante que passa. Há como que uma teia tênue que aproxima as pessoas sem que haja, para isso, uma finalidade específica, pautando-se apenas no prazer de compartilhar, ainda que seja só uma conversa, um "causo", uma risada, todos esses nadas que compõem a vida de todo dia, que, na ausência deles, perde todo o colorido e riqueza. O ser/estar junto se basta. É suficiente saber que o outro está ali, próximo, que posso apreendê-lo com meus sentidos e ser por ele apreendido. E, nesse caso, o espaço faz-se laço, une num mesmo território, propicia a sedimentação, sendo a forma a priori onde se desenham todos os trajetos imaginários ${ }^{(4)}$. 0 espaço no qual essa socialidade acontece, torna-se imbuído de um valor estético (aisthesis) quando vivido junto, fazendo, da pracinha do Hospital, um lugar desprovido de maiores atrativos, um espaço de convivialidade, de troca, de comunhão. No entanto, esse espaço, quando não compartilhado, perde seu sentido religioso (religare), ou seja, de ligação, pois essa "aura" misteriosa que liga, que une, que faz com que, de maneira não consciente, se dividam os sonhos e os fantasmas, lembra a força invisível que permeia os ritos religiosos.

Tenho visto com freqüência o Ifigênio e o Waldecir juntos, tanto assistindo a desenhos animados na televisão que está na enfermaria deles, quanto na área externa, conversando ou brincando. Os dois riem muito quando estão juntos, fazendo brincadeiras com a acompanhante da Rosana, que é uma mocinha bonita. O Waldecir diz que o Ifigênio está apaixonado por ela, e o Ifigênio responde que, na verdade, é o Waldecir que gosta da menina e que não tem coragem para conversar com ela. $E$, hoje, quando fui até a área externa, os dois meninos estavam sentados em um banco, e a mocinha estava em outro, conversando com um rapaz que também é acompanhante de uma pessoa doente da clínica cirúrgica. Parecia que a conversa entre os dois tinha um caráter íntimo, pois os dois se mostravam bastante interessados um no outro. Os meninos olhavam a distância o casal e, de repente, o Waldecir levantou-se e foi até o banco em que eles estavam, sentando-se ao lado deles. Permaneceu assim por algum tempo, depois voltou para junto do Ifigênio, e os dois riram muito da situação. (NOTAS DE OBSERVAÇÃO - 01/02/99)

O lúdico aparece entremeando a vivência da hospitalização, não através de situações estereotipadas, como jogos ou momentos e espaços próprios para o lazer, mas de maneira simples, em instantes de puros prazer pelo ser/estar junto com o outro. Esse instinto vital, irreprimível, de querer viver, irrompe pelos interstícios da vida regrada, normatizada, do Hospital, e se faz presente em pequenos gestos, em rápidos momentos de encontro, até mesmo nos encontros amorosos, não permitidos dentro da instituição, mas que acontecem mascarados, dissimulados.

Hoje permaneci algum tempo na enfermaria das mulheres, conversando com elas, quando o maqueiro veio com a cadeira de rodas para levar a Rosana para fazer uma radiografia. Enquanto eles aguardavam que o pessoal da enfermagem viesse desligar a bomba de infusão endovenosa, por onde a Rosana recebia medicação, ficaram conversando: o maqueiro, que é jovem, a Rosana e a irmã que a acompanha. O rapaz fazia galanteios para a sua irmã e a Rosana ria, parecendo bastante alegre. Ela me disse, durante a entrevista, que são esses momentos de descontração, quando alguém entra na enfermaria e faz algum gracejo, que ajudam a diminuir a dureza da permanência no Hospital. (NOTAS DE OBSERVAÇÃO $-05 / 02 / 99)$

As pequenas transgressões, o jogo da sedução sem maiores conseqüências, fecundam a aridez da permanência no Hospital imprimindo-Ihe algum colorido, constituindo-se em "respiradouros" que permitem, de alguma maneira, oxigenar essa clausura temporária a que se vê submetida a pessoa doente hospitalizada e também quem a acompanha.

Eu me sinto bem, me sinto tranqüilo, tenho pessoas pra conversar. Você aprende mais alguma coisa com eles também, eles ficam assim, meio sozinho, não se sentem bem. A gente conversa, tal, aguarda a decisão. Eu posso ajudar eles, eles pode ajudar eu. Eu fico tranqüilo ali com eles. Comigo, o que precisar, está às ordens. Por exemplo, a parte do Chô Pedro, ele não pode ficar muito sozinho, não agüenta ir no banheiro, tem que uma pessoa ir com ele. (...) Aqui o que mais faço, né, de vez em quando, eu converso com eles, o Jaime, que já vai hoje. Agora eu fico só com o Chô Orlando, Chô Pedro e as pessoas que tão ficando. Conversa né, troca um assunto ali, empresta uma revista pra eles, se eles têm, eles empresta pra mim. (...) Uma pessoa assim, melhor como eu tô sentindo, é não ser uma pessoa zangada, não ser pessoa, assim, mal educada, não ser pessoa ruim. Não tenho esse negócio assim, você tem pra emprestar pra mim, vai empresta. $A$ pessoa ruim não vai querer emprestar, já chega zangado, não sabe como pedir. Pessoa boa pra mim são pessoas legais pra essas coisas. Não são pessoas de conversar o mal, conversar abobrinha. Aí então, pessoa assim, pessoa que é sorridente eu gosto. (IFIGÊNIO)

As admissões e as altas de pessoas doentes no Hospital criam um movimento contínuo de chegadas e partidas, de aproximação e distanciamento, que mostra a efemeridade das relações que aí se estabelecem. É preciso saber incorporar também esse movimento no dia-a-dia, dando o devido valor ao aqui e ao agora, ao momento presente. Se o tempo se mostra impeditivo para a perdurância das relações, há que se "doar" o melhor de si, dentro do limite concedido por ele: o sorriso, a solidariedade, a gentileza, 0 altruísmo. É preciso lembrar que o mecanismo do dom e do contradom é justamente o que cria a vida, o que chama para a vida, pois é necessário que se possa trocar para existir, visto que nossa infinita 
incompletude só pode ser parcialmente superada pela troca com o outro ${ }^{(1)}$. Assim, o ser/estar junto no Hospital leva, também, à partilha dos sofrimentos, à "com-paixão", ou seja, o sentir com e pelo outro.

O movimento de idas e vindas das pessoas doentes, sob o ritmo das admissões e altas hospitalares, faz com que passem a estabelecer relações que se amoldam a essa efemeridade do ser/ estar junto no Hospital.

(...) ele continua lá e hoje ele está mais melhor e já pegou a alta para ir embora, né. Como outro dia eu posso pegar uma alta e ir embora, graças a Deus. É bom pra ele e ruim pra gente, porque acaba, assim, a gente conversar. A gente conversava, né. Fica menos paciente pra gente conversar, ou uma precisão. Aí ele vai embora agradecendo a Deus que saia tudo bem, ai eu também espero que o dia que eu sair, saia tudo bem, igual ao outro. Que saia tudo bem, que nada de mal aconteça. Ai eu peço a graça de Deus que eu saia curado, que nada de mal aconteça, que nem só eu, como as pessoas que estão internadas, que saia tudo bem com elas. (IFIGÊNIO)

Alegra-se com e pelo outro apesar do sentimento ser um tanto ambíguo, pois, indo embora, "perde-se" aquele que the fazia companhia, com quem se compartilhava o quotidiano do Hospital. Ao mesmo tempo, fica-se alegre com sua melhora, sua alta, pois, se hoje é o dia de ele ir embora, amanhã poderá ser o "meu". Abre-se, assim, a esperança de que, nesse círculo de movimento constante do Hospital, "minha hora também chegue".

Mas a partilha exige que se saiba gerir as diferenças de maneira a acomodar os diversos elementos, sentimentos e valores que compõem a ambiência estética (outra maneira de dizer o ser/ estar junto) que serve de moldura a esse processo de atraçãorepulsão, que é o conviver humano. Nesse con-viver, os pólos objetivo e subjetivo têm tendência a se esbaterem, pois 0 acento recai, prioritariamente, sobre aquilo de que todos participam, sobre a soma mais do que sobre as partes ${ }^{(5)}$.

Mas pra todos os efeitos, neste Hospital aqui tem muita gente boa, viu. Muita gente humanitária ainda, gente de bom coração. Como em compensação têm outros que extrapola um pouco, né. A gente não pode querer que tudo seja certinho, não é mesmo? (...) Eu acho que o companheirismo de todo mundo, se ajudar, se colaborar uns com os outros, isso aí tem partes tão bonitas. Nessa parte você vê muitas coisas bonitas aqui ainda. Você vê ainda que tem gente boa neste mundo, gente que colabora com as coisas. Tem também aqueles que não estão nem aí com nada. Se vê você caída lá, dá mais um empurrãozinho para ir logo de cama. Tem outro que vê você precisando de ajuda, corre e estende a mão. (...) Se eu puder ajudar as pessoas, eu ajudo, eu dou uma mão, eu...sei lá! Só que eu não sou muito pra essas coisas assim, sou muito mole, sou muito chorona, sabe. Eu vejo uma pessoa ruim, eu já começo a chorar, já começo a ficar ... Então, às vezes, ao invés de ajudar, eu acabo atrapalhando. E assim é a vida. (GILDA)
Acento trágico de quem conhece o mundo, conhece a vida, e sabe dos limites pessoais, das diferenças individuais e, nem por isso, desacredita do mundo, das pessoas, pois sabe que a gente não pode querer que tudo seja certinho, não é mesmo? Conhece, de um saber incorporado, que há aqueles que são solidários, companheiros, aqueles com quem se pode contar nas horas de necessidade, que vê você precisando de ajuda, corre e estende a mão, como há aquele que dá mais um empurrãozinho para ir logo de cama. Essa razão sensivel que apreende o mundo tal como ele é, sabedora da sua precariedade e impermanência, exprime um tipo de saúde coletiva e um apetite de viver que, sem negar tal paradoxo, relativiza os diversos constrangimentos e oposições sejam eles de que ordem for. Qualquer que seja o nome que se the dê, uma tal força diz, ou não diz, sobretudo no segredo do quotidiano, que essa vida merece, apesar de tudo, ser vivida com intensidade ${ }^{(3)}$.

Vê a outra pessoa com tanto sofrimento, né. Você já tá doente, desanimada, ainda vê outro sofrendo, dai que tu fica desesperada. E você não pode ajudar, não pode fazer nada, só olhando o sofrimento do outro. (...) $E$ a moça que tá lá no isolamento, fica muito triste. Coitada, ela não veio mais aqui no quarto. Ela estava esperando ir embora, estava feliz que ia embora. Acho que ela vai esperar até sexta-feira pra ver o que eles vão falar. (...) Ah! A gente vê tanto caso que são mais triste e a gente que tá mais aliviado, né. Tem tantos que tão pior, que nem sai, que ficam na cama direto. Tem aquele com AIDS também, né, esperando a morte. Que nem um com a perna cortada, agora vai cortar a outra também. Tudo é triste. (MARIA IVONE)

Não se pode fazer nada para minorar o sofrimento do outro, apenas ser solidário, ter com-paixão, ou seja, paixão partilhada, pois ver o outro sofrendo nos afeta também. 0 sofrimento do outro, no entanto, serve de consolo, visto que permite que se conforme com 0 próprio sofrimento, aparentemente menos intenso, pois a gente vê tanto caso que são mais triste e a gente que tá mais aliviado. É necessário lembrar que 0 trágico, o prazer e a solidariedade estão ligados porque se sabe, de um saber incorporado, saber animal, saber do ventre, que aquilo que acontece ao outro, me ameaça igualmente. É isso o destino: "hoje é tua vez, amanhã poderá ser a minha"(3).

Essa identificação, mais forte que a simpatia, que poderia ser chamada de empatia, que faz com que se vibre, se ria, se chore, se grite e se cante juntos, engendrando uma generosidade que nega a egolatria. Indo além de um ínfimo "eu", ela remete em direção ao outro, à alteridade. Esse sentido estético do ser/estar junto, ou seja, as emoções partilhadas que estão presentes nas narrativas das pessoas doentes hospitalizadas, falam das trocas como fundamento da agregação social.

Ontem memo, ontem na hora da janta, eu tava jantando, e o Chô Mário acho que não podia jantar e ele ficava só, assim, espiando. Eu ficava até meio emocionado de vê ele não comendo e eu comendo. Assim, ficava muito triste vendo a pessoa não comer. Ele falava: 'Eu não posso comer comida de sal.' Ele não pode, fica reclamando. Fica ruim pra ele e melhor 
pra mim, só que eu não fico, assim, muito bem vendo as pessoas assim, não. Quero chegar lá e ajudar ele, só que eu não posso, porque ele não pode ficar comendo acho que coisa muito doce também. Aí não posso fazer nada, né. Eu falo: 'Só esperar e acalmar, que um dia o senhor vai sair daqui bom, com a graça de Deus. (IFIGÊNIO)

Se não se pode fazer nada, concretamente, para ajudar 0 outro, resta, pelo menos, uma palavra de consolo, de esperança de melhora. Toda essa ambiência afetual, esse ser/estar junto, essa troca que se estabelece entre as pessoas doentes hospitalizadas, engendra o homem relacional ${ }^{(6)}$, sendo este um misto de abertura e de reserva, com grande tolerância de espírito com relação ao outro, aos outros e àquilo que acontece. A proxemia justifica os intensos investimentos pessoais e interpessoais que se exprimem nesse quotidiano hospitalar, conformando uma comunidade de destino ${ }^{(3)}$, ou seja, empenhado que se está dentro de uma mesma aventura, submetido às mesmas vicissitudes, é também desejável desembaraçar-se o menos mal possível juntos, procurando mais uma acomodação que uma superação da experiência vivida. Essa apropriação coletiva da existência, empreendida pelas pessoas doentes hospitalizadas, embora relativa, se faz pela aceitação da heterogeneidade, do contraditório, com o qual é necessário negociar e, a bem ou mal, entrar em acordo. A beleza do mundo é polissêmica e também ambivalente. É a aceitação de tudo aquilo que, empiricamente, além dos diversos "dever ser" abstratos, constitui o único "dever ser vivido": aquele da complexidade, do contraditorial que não se poderá ser jamais ultrapassado dialéticamente, visto constituir-se na alteridade absoluta que é o fundamento mesmo da humanidade ${ }^{(3)}$.

\section{À GUISA DE CONCLUSÃO}

Tendo aqui apresentado apenas uma faceta desse conviver da pessoa doente com as demais com quem compartilha 0

\section{REFERÊNCIAS BIBLIOGRÁFICAS}

1. Maffesoli M. A conquista do presente. Rio de Janeiro (RJ): Rocco; 1984.

2. Maffesoli M. A sombra de Dionísio. Rio de Janeiro (RJ): Graal; 1985. espaço/tempo do Hospital, pudemos apreender que, a partir da pessoa doente hospitalizada e em torno dela, uma multiplicidade de situações, de experiências, de ações lógicas e não-lógicas têm lugar, constituindo-se num vitalismo que é necessário considerar. Se, a princípio, parecia-nos que as interações que compunham a vivência da hospitalização tinham por fulcro a lógica mecânica que impregna o social, apoiando-se na associação racional de indivíduos mediante um objetivo a cumprir e regras a seguir, entendemos ser necessário, neste momento, relativizar tal percepção. Foi-nos possível compreender que a solidariedade que envolve as pessoas doentes hospitalizadas entre si, desenhando uma comunidade de destino, origina-se de uma união na falta, no vazio, dando lugar a uma comunhão de solidão, cujo acento trágico engendra a fusão. Se essa socialidade não envolve a todos de maneira igualitária é porque ela não se faz no bojo da lógica contratual, mas, sim, no interior de uma lógica afetual que, como já procuramos mostrar, se embasa no sentimento da atração-repulsa, que inclui ou exclui elementos dentro de uma reversibilidade própria.

Entendemos ser importante considerar que, se 0 compartilhar faz sua erupção mesmo através dos rígidos limites impostos pelo Hospital, ao se organizar de maneira racionalista e funcional, ele mostra toda sua força na luta contra o sofrimento, a dor, a solidão e a morte. Esta última pode apresentar-se de maneiras diversas, sejam as "pequenas mortes" quotidianas, representadas pela falta do convívio com a família, a saudade de casa, as muitas incertezas quanto à doença e seu tratamento, seja a verdadeira morte como possibilidade próxima ao se vivenciar a doença. Assim, 0 compartilhar o tempo/espaço no Hospital torna-se uma potência afirmativa que impede a autodestruição, constituindo-se num sair de si e caminhar em direção ao outro, um outro que é diferente em suas necessidades e desejos, bem como em seu manifestar-se, mas que traz a complementaridade necessária para que se engendre essa comunidade de destino composta por aqueles que vivenciam a hospitalização como seu momento presente.

3. Maffesoli M. L'instant eternel. Paris: Denöel; 2000.

4. Durand G. As estruturas antropológicas do imaginário. São Paulo (SP): Martins Fontes; 1997.

5. Maffesoli M. No fundo das aparências. Petrópolis (RJ): Vozes; 1996. 6. Maffesoli M. O tempo das tribos. Rio de Janeiro (RJ): ForenseUniversitária; 1987. 